\title{
Eutrofização dos recursos hídricos como ferramenta para a compreensão das doenças de vinculação hídrica
}

\author{
Aichely Rodrigues da Silva ${ }^{*}$ \\ Alessandra Larissa D’Oliveira Fonseca ${ }^{* *}$
}

\section{Resumo}

O saneamento ambiental inadequado afeta diretamente a qualidade da água e da vida humana. O presente estudo avaliou o estado trófico das águas e as incidências de doenças de vinculação hídrica em bacias hidrográficas com diferentes graus de urbanização na região Norte da Ilha de Santa Catarina, Florianópolis-SC. Foram utilizados o Índice Trófico (Index Trophic - TRIX) e os registros de incidência de doenças de vinculação hídrica disponibilizados pela Secretaria Municipal de Saúde de Florianópolis. No ano de 2014, foram diagnosticados 5.358 casos de diarreia e de gastroenterite na Unidade de Pronto Atendimento - UPA Norte, localizada no bairro de Canasvieiras, bacia hidrográfica do rio Papaquara, onde as águas apresentam características eutróficas. A menor incidência dessas doenças esteve associada a melhor qualidade da água, o que ocorreu no Canal de Jurerê. A pesquisa permitiu alertar para as intervenções necessárias a serem realizadas, tanto pelo serviço de abastecimento sanitário quanto pelo Poder Público, no atendimento aos padrões de qualidade da água estabelecidos pelo CONAMA.

Palavras-chave: Urbanização; Eutrofização; Doenças de vinculação hídrica; Rio Papaquara.

Doutoranda do Programa de Pós-graduação em Geografia da Universidade Federal de Santa Catarina (aichely@gmail.com).

** Professora do Programa de Pós-graduação em Geografia da Universidade Federal de Santa Catarina (alessandra.larissa@ufsc.br).

Geosul, Florianópolis, v. 31, n. 62, p 247-270, jul./ago. 2016 
SILVA, A.R. da \& FONSECA, A.L.D’O. Eutrofização dos recursos hídricos...

Eutrophication of water resources as a tool for understanding waterborne transmission

\section{Abstract}

Inadequate environmental sanitation directly affects water quality and human life. This study evaluated the trophic status and the incidence of water linking conditions in watersheds with different degrees of urbanization in the North of the island of Santa Catarina, Florianópolis-SC. The Trophic Index (TRIX) and information on the incidence of waterborne conditions provided by the Municipal Florianópolis Health were used. In 2014, it was diagnosed 5,358 cases of diarrhea and gastroenteritis in the Emergency Unit - APU North, located in the district of Canasvieiras, watershed of Papaquara river, where the waters have eutrophic features. The lower incidence of disease was associated with improved water quality, which occurred in channel Jurerê. The research allowed to warn the interventions needed to be carried out both by the sanitary service supply as by the Government, in compliance with water quality pattern established by CONAMA.

Key words: Urbanization; Eutrophication; Waterborne transmission; Papaquara River.

\section{Introdução}

No mundo, três milhões e meio de pessoas morrem por ano em consequência de problemas relacionados ao fornecimento inadequado de água, e somente a diarreia, doença relacionada à contaminação da água, provoca 2.195 óbitos de crianças diariamente (TRATA BRASIL, 2015). Esse quadro poderia ser evitado com a melhoria da gestão dos recursos hídricos, abastecimento de água potável, saneamento ambiental e medidas de higiene doméstica (GENTRY-SHIELDS; BARTRAM 2014). No Brasil, 82,5\% da população é atendida com abastecimento de 
SILVA, A.R. da \& FONSECA, A.L.D’O. Eutrofização dos recursos hídricos... água tratada. Por outro lado, somente $48,6 \%$ dessa população tem acesso à coleta de esgoto, sendo que apenas 39\% dos esgotos do país são tratados de forma adequada (SNIS, 2013), o restante é lançado sem tratamento nos corpos hídricos. A falta de tratamento adequado das águas utilizadas para o abastecimento humano pode, ainda, ser decorrente da contaminação pelas pressões negativas na rede, pela falta de esgotamento sanitário e por ligações domiciliares clandestinas (SOARES; BERNANDES; COELHO NETO, 2002).

Hipócrates por volta de 480 a.C na obra "Ares, águas e lugares" abordou o meio ambiente como a gênese, determinação e evolução das doenças, considerando-o como um "elemento" sobre o qual não se exercia nenhum domínio (GOUVEIA, 1999). A geografia da saúde trata dos fatores determinantes em saúde, como as características sociais (escolaridade, renda e outros) e ambientais, dentre eles, a água e os demais elementos que contribuem com o espaço geográfico (SOUZA; ALBUQUERQUE, 2013). No que tange à geografia da saúde, Lacaz (1972) apud Cesa (2012) relata que há interligação entre os conhecimentos geográficos e médicos, o que permite compreender a importância do meio geográfico (antropizado) no surgimento e na difusão de uma determinada doença.

A saúde ambiental integra as dimensões histórica, espacial e coletiva das situações nas quais estão inseridas, a partir da qualidade de vida das populações e dos ecossistemas (AUGUSTO, 2003). Além disso, está relacionada aos fatores físicos, químicos, biológicos, sociais ou psicossociais de um determinado espaço geográfico (OMS, 1998; SOUZA; LIMA, 2013). Com propósito de abordar tal questão, no ano de 2000, o Ministério da Saúde criou o Sistema de Vigilância Ambiental em Saúde, que tem por finalidade adotar medidas de prevenção e controle de doenças relacionadas às variáveis ambientais (BRASIL, 2002). A lei $n^{0} 11.445 / 07$, em seu art. $2^{\circ}$, determina que os serviços públicos de saneamento básico sejam realizados de forma adequada à saúde pública e à proteção do meio ambiente. 
SILVA, A.R. da \& FONSECA, A.L.D’O. Eutrofização dos recursos hídricos...

As áreas densamente urbanizadas são ambientes propícios para a proliferação de doenças devido ao descaso das políticas públicas locais, principalmente nas áreas marginais, que muitas vezes, são locais nos quais a população tem um menor nível educacional e econômico. Além de desconhecer seus direitos, por exemplo, essa população não sabe que tem o direito de viver em um ambiente equilibrado. Aliado a isso, temse o fato de que essa mesma população é agente ativo e passivo dos danos ambientais, o que se reflete na saúde e bem-estar da sociedade. $\mathrm{O}$ despejo de efluentes domésticos e industriais (in natura ou tratados inadequadamente) nos cursos d'água pode motivar a eutrofização antrópica, que é o principal fator do enriquecimento de nutrientes, como fósforo $(\mathrm{P})$ e nitrogênio $(\mathrm{N})$, podendo evoluir para a degradação do ecossistema aquático (TUNDISI; MATSUMURA-TUNDISI, 2011). O fósforo é um nutriente presente nos produtos de limpeza, como os detergentes em pó (SOUZA; CARDOSO; FRAGUAS NETO, 2010); já o nitrogênio é utilizado na agricultura e na indústria, como fertilizante e insumo, respectivamente. Portanto, esses nutrientes artificiais contribuem para o processo de eutrofização artificial, provocando a floração de produtores primários, como as cianobactérias, que liberam toxinas, ou as macrófitas aquáticas. Esse estresse ambiental causa prejuízos para o abastecimento de água e a saúde da população, podendo também levar o ecossistema ao colapso (QUEVEDO; PAGANINI, 2011). A eutrofização artificial ou antropogênica traz riscos para a saúde de forma direta e indireta (CAMARGO; ALONSO, 2006; OMS, 2014). Além disso, provoca alteração na qualidade ambiental e na saúde da população ribeirinha.

A água é um vetor de doenças que são transmitidas pela falta de higiene pessoal e doméstica, deficiência no abastecimento, contato com a água contaminada e com vetores aquáticos (animais e pescados). A quantidade e a qualidade da água são fatores importantes para o estabelecimento de benefícios à saúde, como a redução da incidência e da prevalência de diversas doenças, destacando-se a doença diarreica (QUEIROZ; HELLER; SILVA, 2009), que é uma das principais causas das mortes de crianças pobres menores de 5 anos de idade. É importante destacar que a 
SILVA, A.R. da \& FONSECA, A.L.D’O. Eutrofização dos recursos hídricos... água também é vetor de doenças, como febre tifoide, febre paratifoide, cólera, hepatite, giardíase, esquistossomose, ascaridíase, leptospirose (RAZZOLINI; GÜNTHER, 2008).

A Região Sul do Brasil é caracterizada pela intensa urbanização, contaminação e degradação dos recursos hídricos e dos aquíferos (TUCCI, 2004). A cidade de Florianópolis, no estado de Santa Catarina, dispõe apenas de $46 \%$ de rede coletora de esgoto. Nessa cidade, no ano de 2013, foram diagnosticados quase 8 mil casos, por 100 mil habitantes, de doenças de vinculação hídrica (PNUD, 2015). Por outro lado, o Índice de Desempenho do Sistema Único de Saúde (IDSUS, 2011) relatou que a cidade apresenta 100\% de cobertura em atenção básica de saúde. Sendo assim, o objetivo da pesquisa foi compreender a relação entre a qualidade da água, pelo índice de eutrofização, e a incidência de doenças vinculadas ao meio aquático. $O$ estudo foi desenvolvido em diferentes bacias hidrográficas quanto ao grau de urbanização e quanto à qualidade da água do Norte da Ilha de Santa Catarina (Florianópolis, SC).

\section{Materiais e métodos}

\section{Área de estudo}

As bacias hidrográficas dos rios Papaquara, Ratones, Palha, Canal de Jurerê, Pau-do-Barco e Vadik localizam-se em uma região subtropical, em uma das áreas mais populosas do litoral catarinense: o Norte da Ilha de Santa Catarina (Fig.1). Essas bacias hidrográficas drenam para a Unidade de Conservação - Estação Ecológica de Carijós, que tem um programa de monitoramento de qualidade da água desde 2005. A ESEC Carijós é composta por duas glebas, a do manguezal de Saco Grande e a do manguezal de Ratones. A gleba de Saco Grande possui uma área de 0,93 km², sendo drenada pelos rios Pau-do-Barco e Vadik. Já a gleba de Ratones ocupa uma área de $6,25 \mathrm{~km}^{2}$, para onde deságuam as águas 
SILVA, A.R. da \& FONSECA, A.L.D’O. Eutrofização dos recursos hídricos... dos rios Ratones, Veríssimo e Papaquara, além das águas de um canal de drenagem proveniente do Distrito de Jurerê (SILVA et al., 2013). Essas são áreas pertencentes ao ecossistema costeiro de manguezal, berçário de peixes, moluscos e crustáceos, possuindo, ainda, condições ideais para reprodução, criadouro e abrigo para várias espécies, fauna aquática e terrestre, de valor ecológico e econômico para a região costeira.

Figura 1: Localização da área de estudos indicando os centros de saúde (CS) do norte da Ilha de Santa Catarina e os pontos amostrais de qualidade da água. Os CS estão identificados por cruz e números, sendo: CS Cachoeira do Bom Jesus (1), CS Canasvieiras (2), Unidade de Pronto Atendimento-UPA Norte (3), Policlínica Municipal (4), CS Jurerê (5), CS Vargem Grande (6), CS Vargem Pequena (7), CS Ratones (8) e CS Saco Grande (9); com os cursos d'água Rio Papaquara, Rio Palha, Rio Ratones, Canal Jurerê, Rio Vadik e Rio Pau do Barco e a ESEC Carijós

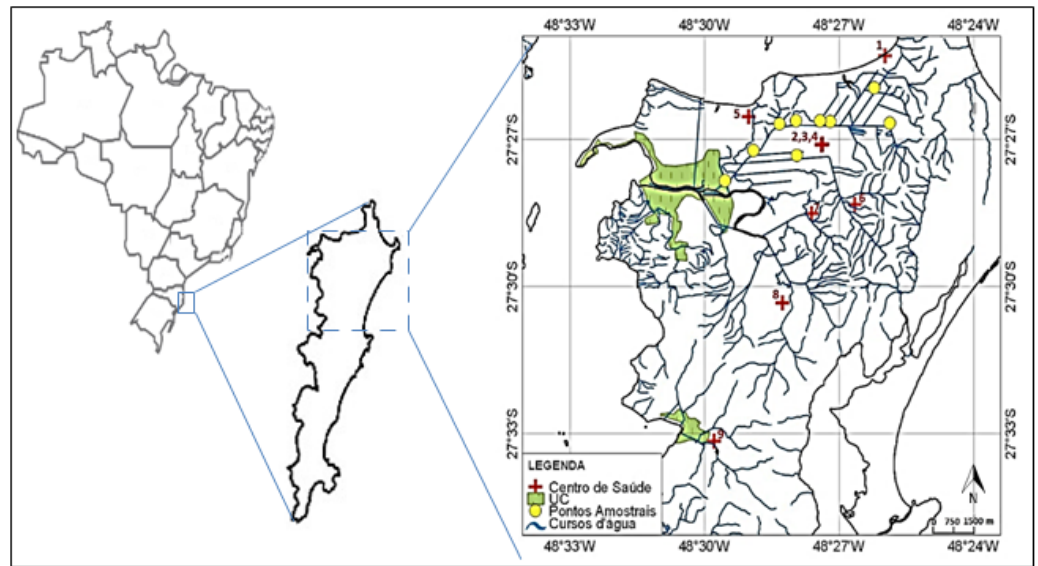

Fonte: EPAGRI (2015) e Secretaria Municipal de Saúde (2015). Adaptado

As bacias hidrográficas mais populosas da área de estudo são a do rio Papaquara, que engloba os bairros de Canasvieiras, 
SILVA, A.R. da \& FONSECA, A.L.D’O. Eutrofização dos recursos hídricos...

Cachoeira do Bom Jesus e Vargem Grande; e a dos rios Pau-doBarco e Vadik, onde localiza-se o bairro Saco Grande. As bacias do rio Papaquara e Pau-do-Barco/Vadik possuem Estações de Tratamento de Esgoto (ETEs) públicas, que tratam 38,9\% e 16,7\% em relação à população por distrito sanitário, respectivamente. $\mathrm{O}$ efluente tratado da ETE Canasvieiras é lançado no interior do rio Papaquara, enquanto que a ETE Saco Grande lança seus efluentes nas águas da Baía Norte (CESA, 2012). O Canal de Jurerê drena o distrito de mesmo nome, possuindo uma ETE de gestão privada que trata os esgotos de aproximadamente 10.000 pessoas no período de veraneio (SAE, 2015).

\section{Dados de qualidade da água e índice trófico}

Os dados de qualidade da água (concentração de nutrientes, oxigênio dissolvido e biomassa fitoplantônica) e do nível trófico das águas, apresentados por Silva et al. (2013) e Silva (2015), foram utilizados neste estudo. Esses autores utilizaram o Índice Trófico (Index Trophic - TRIX), que foi desenvolvido por Vollenweider et al. (1998). Esse índice se baseia na agregação de variáveis biológicas (clorofila- $a$ ) e físico-químicas (oxigênio, nutrientes - NID e PID), para caracterizar o processo de eutrofização das águas costeiras. Esse índice é bastante aplicado em zonas costeiras europeias (Adriático, Tirreno, Báltico, Negro e Mares do Norte). Neste estudo, a qualidade da água foi representada pelo TRIX (Equação 1), que classifica o estado trófico da água costeira em: i) ultraoligotrófico (TRIX $<2)$; ii) oligotrófico $(2-4)$; iii) mesotrófico (4 - 5); iv) mesotrófico a eutrófico (5 - 6); e v) eutrófico (6 - 8) (COTOVICZ JUNIOR et al., 2012). A equação supracitada é a seguinte:

Equação 1 - TRIX $=(\log 10[$ Chl x UAO x DIN x DIP $]+k) / m$

Nessa equação, Chl-a é a concentração de biomassa fitoplantônica (clorofila-a $(\mathrm{mg} / \mathrm{m} 3)$; UAO é o uso aparente do oxigênio ou o desvio da concentração de oxigênio dissolvido, medido na amostra em relação ao valor de saturação; NID é a 
SILVA, A.R. da \& FONSECA, A.L.D’O. Eutrofização dos recursos hídricos... concentração de nitrogênio inorgânico dissolvido $\left(\mathrm{mg} / \mathrm{m}^{3}\right)$; PID é a concentração de fósforo inorgânico dissolvido $\left(\mathrm{mg} / \mathrm{m}^{3}\right)$; 0 coeficiente $\mathbf{k}$ é a soma dos limites mínimos das variáveis; e o $\mathbf{m}$ é o range log das variáveis.

\section{Incidência de doenças de vinculação hídrica}

As informações relativas às incidências de doenças de vinculação hídrica (diarreia, gastroenterite, conjuntivite e micoses), referentes aos anos de 2013 e 2014, foram disponibilizadas pela Secretaria Municipal de Saúde de Florianópolis. Os dados dos Centros de Saúde estavam agrupados em relatórios e foram obtidos pelo software INFOSAUDE, versão 4.0.0.7, no Sistema Municipal de Saúde. Os números de incidência de cada doença foram relativizados em porcentagem, considerando-se quantos habitantes de cada distrito sanitário são atendidos pelo Centro de Saúde (CS).

Nesta pesquisa foram selecionados oito Centros de Saúde, que atendem a população do Norte da Ilha de Santa Catarina, Florianópolis (Fig. 1). Na bacia do Papaquara, foram investigados os Centros de Saúde de Cachoeira do Bom Jesus, de Canasvieiras e da Vargem Grande, além da Policlínica Municipal do Norte da Ilha e da Unidade de Pronto Atendimento (UPA) Norte; já na bacia do rio Palha (afluente do Papaquara), foi investigado o CS da Vargem Pequena; na bacia do Pau-do-Barco e Vadik, considerou-se o CS do Saco Grande. E, por fim, nas demais bacias, o CS recebe o nome igual ao do rio analisado, como o CS Ratones e Jurerê.

\section{Análise estatística}

A Análise de Componentes Principais (ACP) foi gerada a partir do agrupamento dos valores do TRIX para cada rio indicado anteriormente, das porcentagens de cada doença e do número de habitantes por distrito sanitário. O principal objetivo da ACP é indicar quais parâmetros possuem maior "influência” na variância total dos dados (KITSIOU; KARYDIS, 2011). Primeiramente, os dados sofreram transformação logarítmica, a fim de normalizá-los, 
SILVA, A.R. da \& FONSECA, A.L.D’O. Eutrofização dos recursos hídricos... antes de aplicar a análise multivariada. Para isso, utilizou-se o Software MultiVariate Statistical Package (MVSP) 3.0, disponível em: <https://www.kovcomp.co.uk/mvsp/>.

\section{Resultados e discussões}

Os principais corpos hídricos do Norte da Ilha de Santa Catarina, que são o Canal de Jurerê, os rios Papaquara, Pau-doBarco, Ratones, Veríssimo e Vadik, apresentaram a qualidade ambiental comprometida pela interferência antropogênica (SILVA et al., 2013). Somente o Canal de Jurerê (Tab.1) não manifestou estado de eutrofização no período de 2005-2007, quando analisado. Enquanto isso, os rios Vadik e Pau-do-Barco apresentaram o estado mais crítico de qualidade das águas, estando próximos da classificação de hipereutróficos. As águas são classificadas dessa forma quando estão bastante afetadas pela elevada concentração de matéria orgânica e de nutrientes, resultantes da urbanização e da falta de saneamento ambiental adequado. O Índice Trófico (TRIX) aplicado por Silva (2015) mostrou que o rio Papaquara estava em processo de eutrofização, por causa dos impactos oriundos da área interna, mais urbanizada do trecho do rio. Além disso, constatou-se que, nessa área, a qualidade da água mostrou uma piora no período de veraneio, em razão da maior pressão populacional na área pelo turismo.

A região Norte da Ilha de Santa Catarina é abastecida, em sua maioria, por água subterrânea, proveniente de 22 poços artesianos, que formam o Sistema Costa Leste de Abastecimento, cuja capacidade é de 497 l/s (DIÁRIO CATARINENSE, 2014). Isso é preocupante, pois as águas subterrâneas podem estar sendo contaminadas pelas águas superficiais ou pelas fossas sépticas residenciais, que entram em contato com o lençol freático, principalmente, quando consideramos o tipo de sedimentos da região, arenoso, que possui maior capacidade de percolação e contaminação do freático pela água superficial. A região da área de estudos é uma planície de maré, caracterizada por apresentar lençol 
SILVA, A.R. da \& FONSECA, A.L.D’O. Eutrofização dos recursos hídricos... freático superficial e frequentemente alagada pela ação das marés (IPUF, 2010). Além disso, são áreas com restrições de uso e ocupação humana que necessitam de manejo adequado.

A intensa urbanização - aliada ao ineficiente sistema de tratamento de esgoto na área, ao uso das Áreas de Preservação Permanente (APPs) e ao despejo de resíduos sólidos nos corpos hídricos - são as principais alterações antropogênicas nas áreas pesquisadas (CESA, 2012; SILVA, 2015). Neste estudo, o distrito de Canasvieiras apresentou 16.676 habitantes, sendo o mais populoso. O menos populoso foi o distrito sanitário de Ratones, com 2.959 habitantes (Tab. 1). O distrito de Saco Grande foi o que apontou o maior TRIX (de 7,8), sendo que as suas águas foram consideradas eutróficas. Já o distrito com a melhor qualidade ambiental foi o de Jurerê, sendo considerado de mesotrófico a eutrófico.

Tabela 1: População e Índice Trófico das áreas próximas aos centros de saúde, vermelho (Eutrófico) e laranja (Mesotrófico a Eutrófico)

\begin{tabular}{lcc}
\hline \multicolumn{1}{c}{ Centro de Saúde } & População Distrito (2013) & TRIX \\
\hline Cachoeira do Bom Jesus & 5.750 & $\mathbf{7 , 3 ^ { 3 }}$ \\
\hline Canasvieiras & 16.676 & $\mathbf{7 , 3 ^ { 3 }}$ \\
\hline Jurerê & 7.230 & $\mathbf{6 , 0 ^ { 2 }}$ \\
\hline Policlínica & $53.224^{*}$ & $\mathbf{6 , 6}^{2,3}$ \\
\hline Ratones & 2.959 & $\mathbf{6 , 1}^{2}$ \\
\hline Saco Grande & 14.286 & $\mathbf{7 , 8 ^ { 2 , 3 }}$ \\
\hline Upa & $53.224^{*}$ & $\mathbf{6 , 6}^{3}$ \\
\hline Vargem Grande & 4.618 & $\mathbf{6 , 4}$ \\
\hline Vargem Pequena & 1.705 & $\mathbf{6 , 4}$ \\
\hline
\end{tabular}

Fonte: *Soma da população de todos os distritos sanitários do Norte da Ilha de Santa Catarina.

${ }^{1}$ Unidades de Saúde, (PMF, 2013); ${ }^{2}$ Silva et al., (2013) e ${ }^{3}$ Silva (2015).

Conforme a Companhia de Água Catarinense (CASAN), em 2014, foram realizadas inspeções na rede coletora de esgotos no 
SILVA, A.R. da \& FONSECA, A.L.D’O. Eutrofização dos recursos hídricos...

Norte da Ilha de Santa Catarina. Nesse ano, foram constatadas diversas irregularidades nas ligações de esgoto, as quais estavam conectadas à rede pluvial. No bairro Ingleses, $80 \%$ dos estabelecimentos estavam ligados clandestinamente à rede pluvial. Esse percentual foi de $57 \%$ em Canasvieiras e de $68 \%$ em Ponta das Canas e Cachoeira do Bom Jesus. Essa região possui cerca de 34.707 habitantes (IBGE, 2010), sendo que, em média, 68\% dos efluentes domésticos nessa região de Florianópolis não são tratados. Conforme Von Sperling (2005), a contribuição per capita de nitrogênio $(\mathrm{N})$ é de $0,006-0,01 \mathrm{~kg} \cdot \mathrm{hab}^{-1} \cdot \mathrm{d}^{-1}$. e a de fósforo $(\mathrm{P})$ é de $0,0007-0,002 \mathrm{~kg} \cdot \mathrm{hab}^{-1} \cdot \mathrm{d}^{-1}$. Com isso, pode-se estimar que, diariamente, entram aproximadamente $142 \mathrm{~kg}$ de nitrogênio e 17 kg de fósforo, pelos efluentes domésticos, nos corpos hídricos da região.

Na área pesquisada, destaca-se a não aplicabilidade da legislação ambiental vigente na resolução do CONAMA 430/2011, que, no art. $3^{\circ}$, determina que os efluentes de qualquer fonte poluidora somente poderão ser lançados diretamente nos corpos receptores após o devido tratamento. Contudo, com base na classificação dos cursos hídricos de Santa Catarina (o decreto $\mathrm{n}^{\mathrm{o}}$ 14.250/81), o rio Papaquara enquadra-se na classe 1, não devendo, portanto, receber efluentes. A Resolução CONAMA n 357/2005 trata do tema ao orientar que as águas em áreas de proteção ambiental, como a ESEC Carijós para onde drena o rio Papaquara, deveriam ser consideradas de classe especial, pois são destinadas à preservação dos ambientes aquáticos em unidades de conservação de proteção integral e à preservação do equilíbrio natural das comunidades aquáticas.

As águas contaminadas dos cursos d’água deságuam nas praias e nos parques aquícolas, comprometendo, assim, a saúde ambiental e humana. Com base nisso, no ano de 2013, na UPA Norte foram detectados 3.050 casos de diarreia, o que corresponde a 5,73\% da população do distrito de Canasvieiras (Fig. 2). No ano de 2014, esse percentual aumentou para 10,07\%, o que representa 5.358 casos (Fig. 3). A cidade de Florianópolis apresentou seus 
SILVA, A.R. da \& FONSECA, A.L.D’O. Eutrofização dos recursos hídricos...

cursos d’água como impactados pela degradação antropogênica, o que prejudica a balneabilidade ao longo do ano, principalmente no período de veraneio, quando a população flutuante aumenta em 280\% no Norte da Ilha (CAMPANÁRIO, 2007). Conforme relatório de balneabilidade (qualidade das águas destinadas à recreação de contato primário) da Fundação do Meio Ambiente de Florianópolis (FATMA, 2015), a Praia de Pontas das Canas apresentou estado impróprio para o lazer em 18\% e 17\% das amostragens, nos anos de 2013 e 2014, respectivamente. As praias de Jurerê e Canasvieiras apresentaram percentuais parecidos: $15,4 \%$ e $13 \%$ de suas águas estavam impróprias. Ressalta-se a piora da qualidade da água na Praia de Canasvieiras, que, no ano de 2014, teve 16,9\% das amostras consideradas impróprias, devido à presença de coliformes fecais e ao lançamento de efluentes nas águas marinhas.

Figura 2: Percentual de casos de doenças por centro de saúde no ano de 2013.

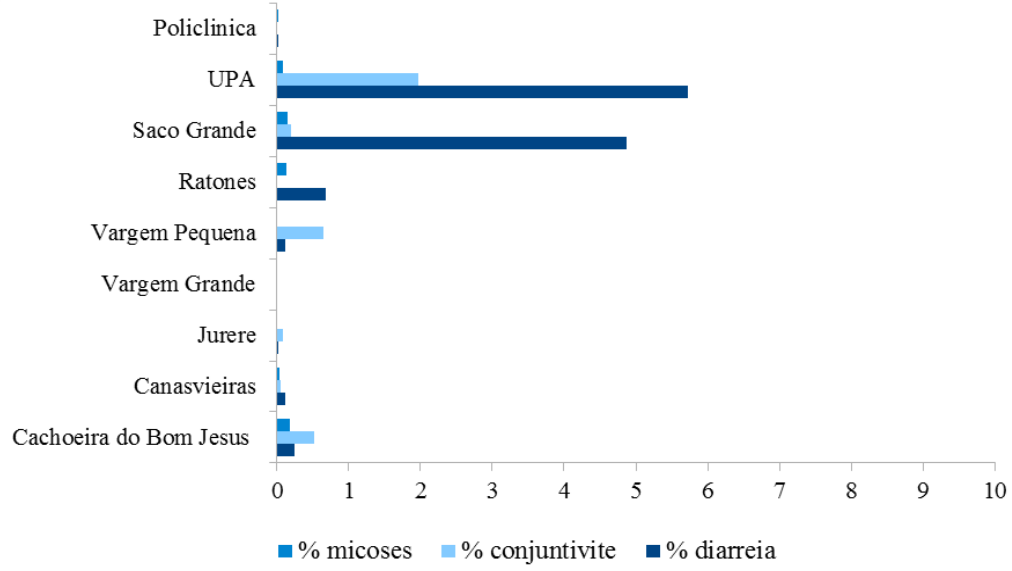

Fonte: Secretaria Municipal de Saúde (2015) 
SILVA, A.R. da \& FONSECA, A.L.D’O. Eutrofização dos recursos hídricos...

Figura 3: Percentual de casos de doenças por centro de saúde no ano de 2014.

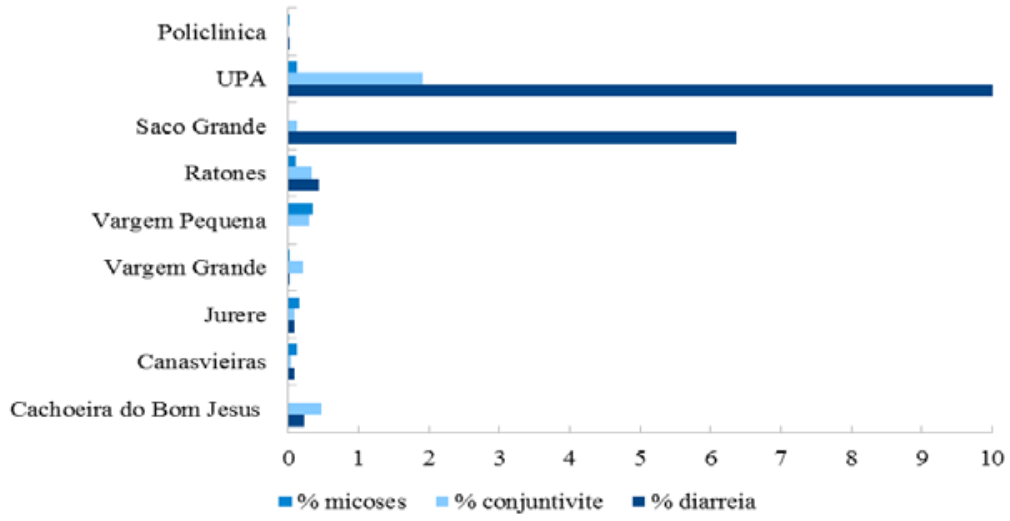

Fonte: Secretaria Municipal de Saúde (2015)

As maiores quantidades de casos de conjuntivite, de 1,97\% em 2013 e de 1,91\% em 2014, foram diagnosticadas na UPA Norte (Fig. 3), totalizando 1.047 casos. Essa doença está relacionada à falta de higiene pessoal e doméstica, além da falta de saneamento básico (FUNASA, 2013). Os casos de micoses, associados ao contato com água ou animais contaminados, foram mais expressivos na UPA Norte (63 casos) no ano 2014. Os números de casos dessas doenças tratadas na pesquisa podem ser inexpressivos nos Centros de Saúde, pelo fato de que muitas pessoas não procuram os Centros de Saúde no caso de doenças cotidianas (VASCONCELOS, 1998).

$\mathrm{Na}$ pesquisa de Corseuil et al. (2009) foram encontradas altas concentrações de coliformes termotolerantes, $\mathrm{DBO}_{5}$ e baixa concentração de oxigênio dissolvido nos diversos pontos do rio Ratones. Essa pesquisa indicou contaminação do corpo hídrico por lançamento de esgoto doméstico, sendo essa a mesma condição encontrada por Silva et al. (2013), além de dejetos de animais. A falta de saneamento ambiental adequado é vetor para as doenças 
SILVA, A.R. da \& FONSECA, A.L.D’O. Eutrofização dos recursos hídricos...

hídricas, especialmente em regiões com más condições higiênicosanitárias (GENTRY-SHIELDS; BARTRAM, 2014).

A Análise de Componentes Principais (Fig. 4) mostrou dois agrupamentos, que estão correlacionados com a qualidade ambiental e a saúde humana. No lado direito do gráfico, para onde convergem a maior população, o maior índice do TRIX e os maiores casos de doenças, identificou-se o CS Saco Grande e a UPA Norte. Nos agrupamentos formados do lado esquerdo do gráfico, encontraram-se os demais Centros de Saúde pesquisados. No quadrante superior direito, os elevados valores do TRIX indicam um pior estado trófico das águas - eutrófico - e estão associados ao CS do Saco Grande. Nesse CS observaram-se os maiores casos (relativos) de micoses. Enquanto que a UPA e a Policlínica Norte atendem a população de diversos bairros da região de estudo, o CS do Saco Grande é exclusivo da comunidade local do bairro, ou seja, esse CS está próximo de um foco de doenças relacionado ao precário abastecimento e tratamento de água na região.

Os casos de diarreias e gastroenterites estão mais associados à UPA, a qual é uma unidade de atendimento emergencial que fica aberta 24h diariamente, atendendo um público que vai além dos bairros vizinhos. Assim, a partir dos resultados, sugere-se que o bairro do Saco Grande deve receber atenção imediata dos órgãos públicos, garantindo o acesso à água tratada de qualidade e o aumento da rede de coleta e tratamento de esgotos domésticos.

Além dessa questão pontual, a área Norte da Ilha de SC apresentou a qualidade das águas comprometida, o que, consequentemente, poderia afetar a saúde da população como um todo. O acesso à água na região não é satisfatório, lembrando que o acesso à água é entendido como o alcance a uma fonte de água, definido no contexto espaço-temporal (CESA, 2012). Razzolini e Günther (2008) destacaram que o difícil acesso a água, caracteriza o consumo como não assegurado, comprometendo a higiene básica e a manipulação dos alimentos, apresentando um grau nocivo muito alto à saúde. 
SILVA, A.R. da \& FONSECA, A.L.D’O. Eutrofização dos recursos hídricos...

Figura 4: Análise de Componentes Principais (ACP) com dados dos centros de saúde, população e percentual de casos de doença pela população nos anos de 2013 e 2014

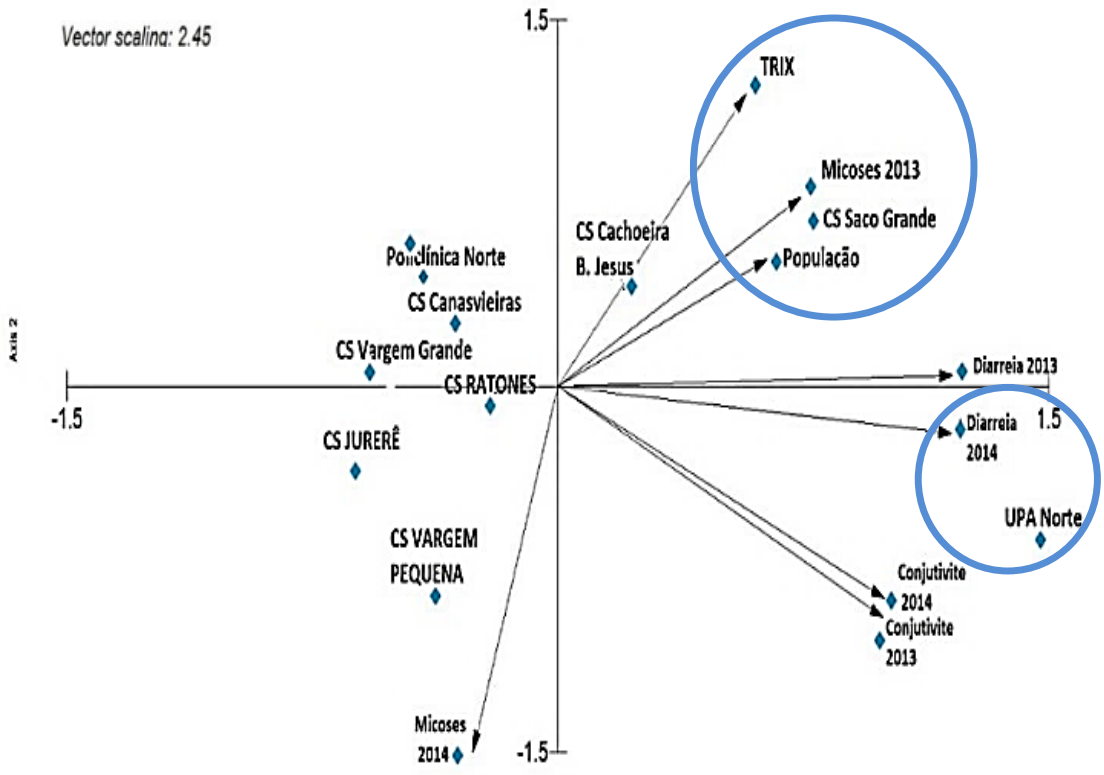

O estado de Santa Catarina é o maior produtor de pescados, ostras, mariscos e mexilhões do Brasil (SC, 2015), produzindo 16.147 t de mexilhão (Perna perna) e ostras (Crassostrea gigas) foi 2.932,5t em 2013. Enquanto que, em 2014 foi de 17.853,1 t de mexilhões e 3.670,36 t de ostras. No município de Florianópolis a produção de mexilhões foi de 1.133 t, em 2013 e de 1.006,1 t no ano 2014. A produção de ostras foi de 2.033 t no ano 2013 e de 2.707,46 t em 2014 (EPAGRI, 2013; 2014). A maior parte dessa produção ocorre nos parques aquícolas da Baía Norte e Sul da Ilha de SC, estando sujeita à contaminação vinda dos rios que ali deságuam, como os rios avaliados neste estudo. Coelho et al. (2003) relataram que as ostras (Crassostrea gigas) cultivadas em SC foram capazes de acumular o vírus da hepatite A em seus tecidos, o que é resultado das águas contaminadas por 
SILVA, A.R. da \& FONSECA, A.L.D’O. Eutrofização dos recursos hídricos... esgotos, já que elas são bioindicadoras da qualidade da água pela capacidade de bioacumular contaminantes e patógenos (LEAL; FRANCO, 2008; RIGOTTO et al., 2010). Além disso, em áreas de cultivo de moluscos localizadas em baías, que são ecossistemas muito sensíveis às pressões antrópicas, pois são áreas semifechadas que estão recebendo uma forte pressão antrópica. A característica geográfica das baías favorece à presença de altas concentrações de material particulado e pouca circulação de água (FERREIRA; OLIVEIRA NETO, 2007). Nos ambientes eutrofizados ocorrem, também, as florações de cianobactérias podem produzir cianotoxinas, neurotóxicas e hepatotóxicas, sendo que as primeiras podem causar a morte em mamíferos por parada respiratória em poucos minutos (LOPES; MAGALHÃES JR; VON SPERLING, 2013).

Os rios avaliados nesta pesquisa drenam para áreas próximas às fazendas aquícolas de Santo Antônio de Lisboa e Sambaqui, o que gera conflitos de uso desse espaço. Apesar do quadro de contaminação observados nos rios que drenam para a Baía Norte. Jacomel e Campos (2014) indicaram que todas as localidades de Santa Catarina que foram monitoradas pelo Programa Nacional de Controle HigiênicoSanitário dos Moluscos Bivalves (PNCMB) apresentaram condições boas e/ou aceitáveis em seu histórico de resultados.

Os atrativos de Florianópolis, como o lazer e a pesca, são dependentes de água com boa qualidade, conforme CONAMA (Resol. 357/2005). Segundo o Ministério do Turismo (2013), Florianópolis ocupa a segunda colocação geral nacional das cidades com a maior demanda turística internacional, com 18,1\% das visitas internacionais que reforça a importância da indústria do turismo para a região. Portanto, com a deterioração da qualidade da água dos recursos hídricos, além de prejudicar a saúde humana, favorece as perdas econômicas e dos bens e serviços ecossistêmicos. Torna-se emergencial a intervenção do poder público e a mobilização dos cidadãos, muitos dos quais não destinam seus efluentes domésticos de forma correta (como já indicado anteriormente) para reverter o quadro de degradação dos recursos hídricos na região. 
SILVA, A.R. da \& FONSECA, A.L.D’O. Eutrofização dos recursos hídricos...

\section{Conclusão}

Este estudo indicou a necessidade imediata de intervenções do Poder Público no serviço de abastecimento e de tratamento da água no Norte da Ilha de Santa Catarina, a fim de garantir os padrões de qualidade da água e de minimizar as incidências de doenças de vinculação hídrica. O TRIX, além de indicar um estado de qualidade ambiental, a eutrofização, também serviu como uma ferramenta para avaliar a qualidade da saúde dos moradores da bacia hidrográfica em estudo.

Recomenda-se a realização de estudos que busquem identificar as variáveis capazes de identificar a correlação dessas doenças de vinculação hídrica com as variáveis sociais, como condições de moradia e Índice de Desenvolvimento Humano. Este estudo não tratou dos casos de doenças registrados pelos Agentes Comunitários de Saúde nos domicílios e nem focou nos casos cujos habitantes residem em domicílios que utilizam fontes de água diretamente do rio, muito comum nas áreas altas das bacias hidrográficas, condições que precisam ser avaliadas para aprimorar os resultados aqui obtidos.

\section{Agradecimentos}

A CAPES pelo fomento a bolsa de mestrado. Ao INCTTMCOcean (CNPq 484956/2012-4) pelo auxílio financeiro na excursão da pesquisa. A Estação Ecológica de Carijós e a Secretária Municipal de Saúde de Florianópolis pela disponibilidade dos dados.

\section{Referências bibliográficas}

AUGUSTO, L. G. da S. Saúde e Vigilância Ambiental: um tema em construção. Epidemiologia e Serviços de Saúde, v. 12, n. 4, p.177 - 187, 2003. 
SILVA, A.R. da \& FONSECA, A.L.D’O. Eutrofização dos recursos hídricos... BRASIL. CONAMA, Conselho Nacional do Meio Ambiente. Resolução $n^{\circ}$ 357, de 17 de março de 2005.

BRASIL. CONAMA. RESOLUÇÃO $n^{0}$ 430, de 13 de maio de 2011.

<http://www.mma.gov.br/port/conama/res/res11/propresol_lancefl ue_30e31mar11.pdf>. Acesso em: 01 jul. 2015.

BRASIL. Fundação Nacional de Saúde. Resíduos sólidos e a saúde da comunidade: informações técnicas sobre a interrelação saúde, meio ambiente e resíduos sólidos. Fundação Nacional de Saúde - Brasília: Funasa, 2013.44p

BRASIL. Lei no 11445 de 05/01/2007. Lei do Saneamento. Estabelece diretrizes nacionais para o saneamento básico. Disponível em: < http://www.planalto.gov.br/ccivil_03/_ato20072010/2007/lei/l11445.htm>. Acesso em: 11 jun. de 2015.

BRASIL. Ministério da Saúde. Disponível em: $<$ http://portalsaude.saude.gov.br/>. Acesso em: 01 jun. de 2015

BRASIL. Ministério do Turismo. São Paulo e Rio de Janeiro lideram turismo no Brasil. Disponível em: <http://www.brasil.gov.br/turismo/2013/09/sao-paulo-e-rio-dejaneiro-lideram-turismo-no-brasil>. Acesso em: 03 ago. 2015

CAMARGO, J. A.; ALONSO, Á. Ecological and toxicological effects of inorganic nitrogen pollution in aquatic ecosystems: A global assessment. Environment International, v. 32, p. 831-849, 2006.

CAMPANÁRIO, P. Florianópolis: dinâmica demográfica e projeção da população por sexo, grupos etários, distritos e bairros (1950-2050). Prefeitura de Florianópolis: Instituto de Planejamento de Florianópolis (IPUF), 2007. 
SILVA, A.R. da \& FONSECA, A.L.D’O. Eutrofização dos recursos hídricos...

CASAN. Fiscalização revela que irregularidades nas ligações de esgoto chegam a $\mathbf{8 0} \%$. Disponível em: http://www.casan.com.br/ noticia/index/url/fiscalizacao-revela-que-irregularidades-nas-ligacoesde-esgoto-chegam-a-80\#0. Acesso em: 08 jul.2015.

CESA, M. de V. Água e outros fatores socioambientais na ocorrência das doenças de vinculação hídrica na Ilha de Santa Catarina. Tese (Doutorado em Geografia). Universidade Federal de Santa Catarina, 2012.

COELHO, C.; HEINERT, A.P.; SIMÕES, C.M.O.; BARARDI, C.R.M. Hepatitis A virus detection in oysters (Crassostrea gigas) in Santa Catarina State, Brazil, by reverse transcription polymerase chain reaction. J Food Prot, V. 66, p. 507-511, 2003

CORSEUIL, C. W.; LIBOS, N. C.; FUZINATTO, C. F.; PINTO, C. R. da S. de C. Distribuição espacial do índice de qualidade da água e a relação com o uso e ocupação do solo da bacia hidrográfica do rio Ratones. Anais... XIV Simpósio Brasileiro de Sensoriamento Remoto, Natal, Brasil, 2009.

COTOVICZ JUNIOR, L. C.; BRANDINI, N.; KNOPPERS, B. A.; FRIEDERICHS, W.; SOUZA, L. de; MEDEIROS, P. R. P. Comparação de Modelos e Índices para Avaliação do Estado Trófico do Complexo Estuarino-Lagunar Mundaú-Manguaba, (AL). Geochimica Brasiliensis, v. 26, n.1, p. 7-18, 2012. 
SILVA, A.R. da \& FONSECA, A.L.D’O. Eutrofização dos recursos hídricos...

DIÁRIO CATARINENSE. Sistema da Casan é insuficiente para tratar quantidade de água de mananciais da Ilha de Santa Catarina. 10/11/2014.

Disponível

em:

$<$ http://diariocatarinense.clicrbs.com.br/sc/economia/noticia/2014/

11/sistema-da-casan-e-insuficiente-para-tratar-quantidade-de-aguade-mananciais-da-ilha-de-santa-catarina-4639989.html>. Acesso em: 03 ago. 2015.

EPAGRI. Empresa de Pesquisa Agropecuária e Extensão Rural de Santa Catarina Síntese Informativa da Maricultura 2013 e 2014. Disponível em: <http://www.epagri.sc.gov.br/wpcontent/uploads/2013/08/S\%C3\%ADntese_informativa_da_maricu ltura_2014.pdf. > Acesso em 25 jun. de 2015.

FATMA. Balneabilidade nas praias do Norte da Ilha de Santa Catarina.

<http://www.fatma.sc.gov.br/laboratorio/dlg_balneabilidade2.php. Acesso em: 04 ago. 2015.

FERREIRA, J. F.; OLIVEIRA NETO, F. M. de. Cultivo de moluscos em Santa Catarina. In: BARROSO, G. F.; POERSCH, L. H. da S.; CAVALLI, R. O. (Orgs). Sistemas de cultivos aqüícolas na zona costeira do Brasil: recursos, tecnologias, aspectos ambientais e sócio-econômicos. Rio de Janeiro: Museu Nacional, 2007(Série livros 26).

Disponível em: https://www.researchgate.net/profile/Luis_Poersch/publication/443 58595_Sistemas_de_cultivos_aqucolas_na_zona_costeira_do_Bras il_recursos_tecnologias_aspectos_ambientais_e_socioeconomicos_organizadores_Gilberto_Fonseca_Barroso_Lus_Hen rique_da_Silva_Poersch_Ronaldo_Olivera_Cavalli/links/0a85e531 fc1ca87d12000000.pdf\#page=84. Acesso em: 01 jun. 2016.

GENTRY-SHIELDS, J.; BARTRAM, J. Human health and the water environment: Using the DPSEEA framework to identify the 
SILVA, A.R. da \& FONSECA, A.L.D’O. Eutrofização dos recursos hídricos... driving forces of disease. Science of the Total Environment, v.468-469, p. 306-314, 2014.

GOUVEIA, N. Saúde e meio ambiente nas cidades: os desafios da saúde ambiental. Saúde e Sociedade, v. 8, n.1, p- 49-61, 1999.

Índice de Desempenho do Sistema Único de Saúde. IDSUS Florianópolis 2011. Disponível em: <http://idsus.saude.gov.br/mapas.html>. Acesso em: 04 jul. 2015.

Instituto de Planejamento Urbano de Florianópolis. IPUF. Atlas de Florianópolis. Disponível em: $<$ https://parquemunicipalmacicodacosteira.files.wordpress.com/20 10/05/atlas_ipuf.pdf >. Acesso em: 05 ago. 2015.

JACOMEL, B.; CAMPOS, L. M. de S. Produção sustentável e controlada de ostras: ações em Santa Catarina (Brasil) rumo aos padrões internacionais de comercialização. Revista de Gestão Costeira Integrada, v.14, n.3, p.501-515, 2014.

KITSIOU, D.; KARYDIS, M. Coastal marine eutrophication assessment: a review on data analysis. Environment International, v. 37, p.778-801, 2011.

LEAL, D. A. G.; FRANCO, R. M. B. Moluscos bivalves destinados ao consumo humano como vetores de protozoários patogênicos: Metodologias de detecção e normas de controle. Rev Panam Infectol., v.10, n. 4, p.48-57, 2008.

LIMA, S. do C. Saúde ambiental e as transformações socioambientais na Amazônia. In: OLIVEIRA, J. A. de (org.). Espaço, saúde e ambiente na Amazônia: ensaio de geografia da saúde. São Paulo: Outras Expressões, 2013 (Geografia e Movimento). 
SILVA, A.R. da \& FONSECA, A.L.D’O. Eutrofização dos recursos hídricos... LOPES, F. W. de A.; MAGALHÃES JR, A. P.; VON SPERLING, E. Balneabilidade em águas doces no brasil: riscos à saúde, limitações metodológicas e operacionais. Hygeia, v. 9, n.16, p.28 47, 2013.

Organização Mundial da Saúde. OMS. Guidelines for drinkingwater quality. Disponível em: http://www.who.int/wa ter_sanitation_health/publications/2011/dwq__ guidelines/en/. Acesso em 10JUN2015. Acesso em: 10 jun. 2015.

PNUD BRASIL. Objetivos de desenvolvimento do milênio. Disponível em: <http://www.relatoriosdinamicos.com.br/portalodm/>. Acesso em: 01 jun. de 2015.

\section{PREFEITURA MUNICIPAL DE FLORIANÓPOLIS. Unidade de} Saúde.

Disponível: http://www.pmf.sc.gov.br/sistemas/saude/unidades_saude/populaca o/uls_2013_index.php. Acesso em: 20 jun. 2015

QUEIROZ, J. T. M. de; HELLER, L.; SILVA, S. R. da. Análise da Correlação de Ocorrência da Doença Diarreica Aguda com a Qualidade da Água para Consumo Humano no Município de Vitória-ES. Saúde Soc., v.18, n.3, p.479-489, 2009.

QUEVEDO, C. M. G. de; PAGANINI, W. da S. Impactos das atividades humanas sobre a dinâmica do fósforo no meio ambiente e seus reflexos na saúde pública. Ciênc. Saúde Coletiva, v.16, n.8, 2011.

RAZZOLINI, M. T. P.; GÜNTHER, W. M. R. Impactos na saúde das deficiências de acesso à água. Saúde Soc. São Paulo, v.17, n.1, p.21-32, 2008.

RIGOTTO, C.; VICTORIA, M.; MORESCO, V.; KOLESNIKOVAS, C.K.; CORREA, A.A.; SOUZA, D.S.M.; 
SILVA, A.R. da \& FONSECA, A.L.D’O. Eutrofização dos recursos hídricos... MIAGOSTOVICH, M.P.; SIMÕES, C.M.O.; BARARDI, C.R.M. Assessment of adenovirus, hepatitis A virus and rotavirus presence in environmental samples in Florianópolis, South Brazil. Journal of Applied Microbiology, v.109, p.1979-1987, 2010.

SANTA CATARINA (Estado). Decreto Estadual n. 14.250, de 5 de junho de 1981. Regulamenta dispositivos da Lei n. 5.793, de 15 de outubro de 1980, referentes à proteção e à melhoria da qualidade ambiental. Diário Oficial do Estado, Florianópolis, 9 jun. 1981.

Secretaria de Estado da Agricultura e da Pesca. Secretaria da Agricultura comemora os resultados da safra 2013/2014. Publicado em quinta, 15 de janeiro de 2015. Disponível em: http://sc.gov.br/mais-sobre-agricultura-e-pesca/secretaria-daagricultura-comemora-os-resultados-da-safra-2013-2014. Acesso em: 05 jun. 2015

SILVA, A. R. DA; KNIESS, D. C.; RIGOTTI, J. A.; FONSECA, A. L. D. Aplicação do modelo TRIX para avaliação da qualidade da água dos rios que drenam para Estação Ecológica de Carijós, Florianópolis, SC, Brasil. Anais...XX Simpósio Brasileiro de Recursos Hídricos, Bento Gonçalves -RS, 2013.

SILVA, A.R. da. Avaliação da qualidade ambiental e do processo de eutrofização na bacia hidrográfica do Papaquara, Ilha de Santa Catarina, SC. Dissertação (Mestrado em Geografia). Universidade Federal de Santa Catarina, 2015. 123p.

Sistema de Abastecimento de Água e Esgoto. SAE HABITASUL. Disponível em: <http://www.jurere.com.br/sae/eta.htm>. Acesso em: 05 ago. 2015.

SOARES, S. R. A.; BERNARDES, R. S.; CORDEIRO NETTO, O. de M. Relações entre saneamento, saúde pública e meio ambiente: elementos para formulação de um modelo de 
SILVA, A.R. da \& FONSECA, A.L.D’O. Eutrofização dos recursos hídricos... planejamento em saneamento. Cad. Saúde Pública, v. 18, n.6, p.1713-1724, 2002.

SOUZA, R. F. de; ALBUQUERQUE, A. R. da C. Abordagem geográfica em saúde aplicada ao controle vetorial da dengue em Manaus/AM. In: OLIVEIRA, J. A. de (org). Espaço, saúde e ambiente na Amazônia: ensaio de geografia da saúde. São Paulo: Outras Expressões, 2013 (Geografia e Movimento).

TRATA BRASIL. Análise dos impactos na saúde e no sistema único de saúde decorrentes de agravos relacionados a um esgotamento sanitário inadequado dos 100 maiores municípios brasileiros no período 2008-2011. Relatório Final, 2013.

TUNDISI, J. G. Água no século XXI: enfrentando a escassez. São Carlos: Rima, 2003.

VASCONCELOS, E. M. Educação popular como instrumento de reorientação das estratégias de controle das doenças infecciosas e parasitárias. Cad. Saúde Pública, v. 14, n. 2, p. 39-57, 1998.

VOLLENWEIDER, R. A.; GIOVANARDI, F.; MONTANARI, G.; RINALDI, A. Characterization of the trophic conditions of marine coastal waters with special reference to the Nw Adriatic Sea: proposal for a trophic scale, turbidity and generalized water quality index. Environmetrics, n. 9, p.329-357, 1998.

VON SPERLING, M. Princípios do tratamento biológico de aguas residuárias. In: Introdução à qualidade das águas e ao tratamento de esgoto. $3^{a}$ ed. Minas Gerais: Departamento de Engenharia Sanitária e Ambiental - UFMG, v.1, 452 p, 2005.

Recebido em setembro de 2015

Aceito em abil de 2016 